\title{
Expression of tissue transglutaminase in the developing chicken limb is associated both with apoptosis and endochondral ossification
}

\author{
Vilmos A. Thomázy ${ }^{1}$ and Peter J.A. Davies ${ }^{\star, 1}$ \\ ${ }^{1}$ Department of Integrative Biology, Pharmacology and Physiology, University \\ of Texas-Houston, Medical School, Houston, Texas 77225, USA \\ * corresponding author: Dr. Peter J.A. Davies, Department of Pharmacology, \\ University of Texas-Houston, Medical School, P.O. Box 20708, Houston, Texas \\ 77225, USA. tel: (713) 500-7480; fax: (713) 500-7455; \\ e-mail: pdavies@farmr1.med.uth.tmc.edu
}

Received 24.8.98; revised 25.11.98; accepted 12.10.98

Edited by G. Melino

\begin{abstract}
The cross-linking enzyme tissue transglutaminase (tTG) participates in a variety of cellular functions. To assess its contribution to extracellular and intracellular processes during development we cloned the CDNA for chicken heart tissue transglutaminase and localized the sites of transglutaminase expression by in situ hybridization and immunohistochemistry. Compared with the chicken red blood cell transglutaminase CDNA, the heart cDNA encodes a transglutaminase with an amino-terminal truncation. The truncated enzyme retains full catalytic activity and is GTP-inhibitable. Tissue transglutaminase expression was observed in developmentally transient structures in embryonic chicken limb at day 7.5 of incubation suggesting that its expression is dynamically regulated during limb morphogenesis. The major morphogenetic events of the limb associated with transglutaminase expression were cartilage maturation during skeletal development, interdigital apoptosis, and differentiation of skeletal muscle. Maturation of the cartilage during endochondral ossification was characterized by intra- and extracellular transglutaminase accumulation in the zone of hypertrophic chondrocytes. Only intracellular enzyme could be detected in mesenchymal cells of the prospective joints, in apoptotic cells of the interdigital web, and in skeletal muscle myoblasts. An apparently constitutive expression of tissue transglutaminase was found in vascular endothelial cells corresponding to the adult expression pattern. The dynamic pattern of transglutaminase expression during morphogenesis suggests that tissue remodeling is a major trigger for transglutaminase induction.
\end{abstract}

Keywords: tissue transglutaminase; cDNA; apoptosis; cartilage; chicken embryo

Abbreviations: tTG, tissue transglutaminase; E7.5, embryonic day 7.5

\section{Introduction}

Transglutaminases (E.C 2.3.2.13) are $\mathrm{Ca}^{2+}$-dependent enzymes which introduce covalent $N \gamma$-( $\varepsilon$-glutaminyl)lysine cross-links into proteins by modifying peptide-bound glutamine residues to form stable polymeric structures. ${ }^{1,2}$ The cross-linked proteins are involved in a diverse array of both intracellular and extracellular physiological processes. ${ }^{3,4}$ Some of these cross-linking reactions are catalyzed by very specialized transglutaminases that are expressed and activated in unique tissue compartments. For instance the coagulating gland of the prostate secretes a specific transglutaminase that is activated in semen and contributes to the formation of the copulatory plug in rodents. ${ }^{5,6} \mathrm{~A}$ distinct extracellular transglutaminase, factor XIIla, is present in plasma and is activated during blood clotting. ${ }^{7,8}$ This enzyme appears to be responsible for the cross-linking of plasma and matrix proteins involved in hemostasis and wound healing. ${ }^{9,10}$ In addition to these extracellular transglutaminases, there are several intracellular transglutaminases that are also involved in very specialized cross-linking reactions. Keratinocyte transglutaminase ${ }^{11,12}$ is an intracellular enzyme that is induced during the terminal differentiation of squamous epithelial cells. Activation of this enzyme and the subsequent cross-linking of keratinocyte-specific substrate proteins lead to the formation of the cornified envelope that invests the interior of the differentiated cell. ${ }^{13}$

In contrast to these specialized enzymes, tissue transglutaminase (tTG) is a transglutaminase that is expressed in many cells and tissues and has been implicated in both intracellular and extracellular crosslinking reactions. Studies on the localization of tTG have demonstrated that the enzyme can be found both inside cells, where it is predominantly associated with the cytoplasm ${ }^{14-16}$ as well as in the extracellular space. ${ }^{17,18}$ Extracellular tTG appears to be tightly bound to matrix proteins $^{19,20}$ and has been implicated in both the crosslinking of matrix proteins ${ }^{17,21,22}$ and the activation of cytokines. $^{23}$ Intracellular tTG has also been implicated in the cross-linking of cytoplasmic proteins during apopto$\operatorname{sis}^{24,25}$ and in GTP-dependent regulation of phospholipase C activity. ${ }^{26}$

Much of the information on the functions of tTG has been derived from pharmacological or pathological studies, in which the expression of the enzyme has been characterized in drug-treated cells or in tissues responding to injury. In many of these situations the enzyme has appeared to be involved in tissue remodelling. ${ }^{27-31}$ To determine if tissue transglutaminase plays an equivalent role in physiological remodelling processes such as those that occur during normal development, we have characterized the patterns of expression of the enzyme in the 
developing chicken limb. We observed the selective expression of transglutaminase during deletion of the interdigital web by apoptosis, during the formation of the specialized extracellular matrix of the hypertrophic cartilage, and in differentiating myoblasts of the limb's skeletal muscle.

\section{Results}

\section{Cloning and sequencing of chicken heart cDNA}

To characterize the expression of $\mathrm{tTG}$ in the developing limb of the chicken embryo we cloned its gene from a $\lambda Z A P$ chicken heart cDNA library using a mouse macrophage tTG cDNA as a probe. We obtained a $2.8 \mathrm{~kb}$ partial chicken transglutaminase clone which we used to rescreen the library

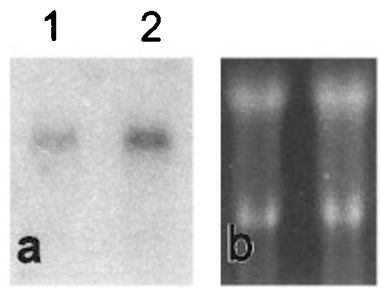

Figure 1 Detection by Northern blotting of tissue transglutaminase mRNA in embryonic and hatchling chicken heart (a). Ten $\mu \mathrm{g}$ of total RNA prepared from the heart of day 13 embryos (lane 1), or day 4 hatchlings (lane 2) were separated on formaldehyde-agarose gel, transferred to nylon membrane and probed with a heat-denatured $\alpha-{ }^{32} \mathrm{PdATP}$-labeled chicken heart transglutaminase cDNA probe. A single mRNA species of $3.2 \mathrm{~kb}$ was detected in the total heart RNA. (b): Visualization of the corresponding lanes by ethidium bromide staining to yield a full length transglutaminase cDNA clone (ctg12) of $2.8 \mathrm{kbp}(2810 \mathrm{nt})$. The nucleotide sequence of several overlapping cDNA clones identified a consensus sequence that included 33 nucleotides of 5 '-untranslated DNA, an open reading frame of 2067 nucleotides encoding a protein of 689 residues and $710 \mathrm{nt}$ of $3^{\prime}$-untranslated DNA. The translation start site conformed to a Kozak consensus sequence (ACCATGG) for translation initiation. ${ }^{42}$

Comparison of the chicken heart cDNA sequence to that of the chicken red blood cell transglutaminase (CRBCTG ${ }^{43}$ revealed that both transglutaminases have very similar coding and 3 -untranslated sequences. Of the nine single nucleotide differences detected in the coding sequence, two would result in amino acid substitutions, Ala24 and Ser109 of the heart enzyme for Glu and Ile, respectively, in CRBCTG. The 5'-ends of the chicken heart and chicken red blood cell cDNAs diverged 20 nt upstream of the translation start site.

Northern blot analysis of day 13 embryonic chicken heart RNA revealed a single band of $3.2 \mathrm{~kb}$ when probed with ctg12 cDNA (Figure 1) demonstrating that there was a single species of tissue transglutaminase message in the heart.

To determine if the chicken heart cDNA encoded an active transglutaminase, COS-1 cells were transfected with an expression vector in which the chicken heart cDNA was inserted under the control of the SV40 promoter (pSG5/ cTG). Comparison of the transglutaminase activity of cells transfected with pSG5/cTG with control cells demonstrated a 40-fold increase in transglutaminase activity in the cells transfected with the transglutaminase cDNA relative to the endogenous transglutaminase level (Figure 2a). Twohundred $\mu \mathrm{M}$ GTP- $\gamma$-S inhibited the activity of the overexpressed enzyme $92.9 \%$ (not shown). Immunoblot a

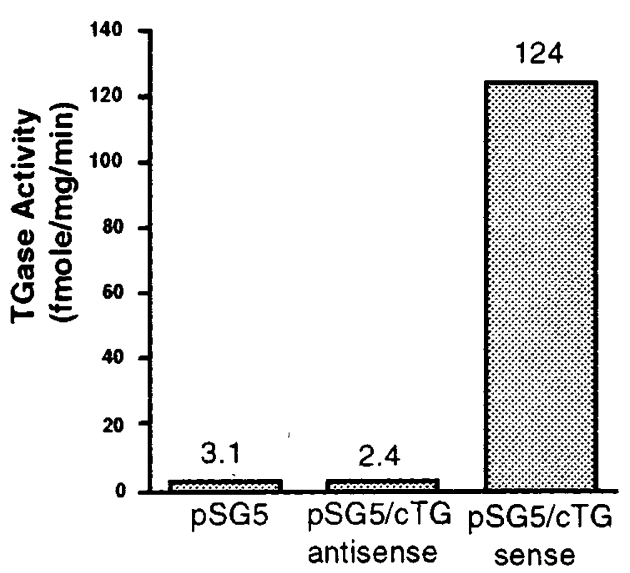

b

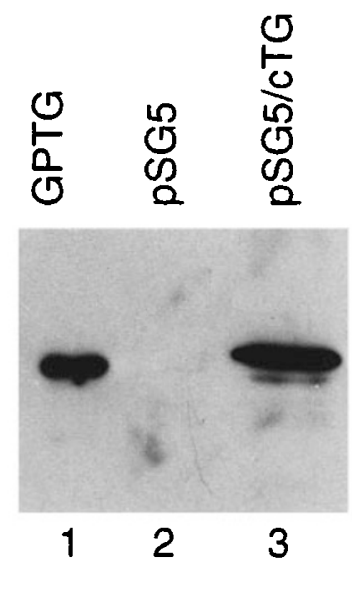

Figure 2 (a and $\mathbf{b}$ ) Expression of chicken heart cDNA in COS1 cells. Chicken heart transglutaminase cDNA inserted into the pSG5 eukaryotic expression vector was transfected into COS1 cells by the DEAE-dextran method in a transient transfection experiment. Three days after transfection cell lysates were prepared and assayed for transglutaminase activity (a) and for immunodetectable protein by immunoblotting (b). (a) Transglutaminase assay of COS1 cells transfected with the heart transglutaminase cDNA in the correct orientation (pSG5/cTG sense) shows a 40-fold increase in the covalent conjugation of [ ${ }^{3} \mathrm{H}$ ]putrescine to dimethylated casein compared with cells transfected with the vector (pSG5) or the antisense construct (pSG5/cTG antisense). (b) Immunoblotting of lysates of the transfected cells with an affinity purified goat anti-guinea pig liver transglutaminase antibody detects an immunoreactive band of $80 \mathrm{kDa}$ in cells transfected with the sense transglutaminase expression construct (lane 3) but not in lysate prepared from cells transfected with the vector alone (lane 2 ). Lane 1 contains 20 ng of purified guinea pig liver transglutaminase 
analysis of cytosols from control cells (lane 2) and cells transfected with the cTG expression vector (lane 3) revealed the presence of a single band of chicken transglutaminase with electrophoretic mobility very similar to the guinea pig transglutaminase standard (lane 1) (Figure 2b).

\section{Expression of tissue transglutaminase in the chicken limb}

The goal of these studies was to characterize the expression of tissue transglutaminase in the developing chicken limb. Figure 3 compares the level of tTG in proximal and distal limb segments with the levels of the enzyme in heart, liver and brain tissues isolated from day 7.5 chicken embryos (E7.5). Both the distal and proximal limb structures contain immunoreactive tTG. The concentration of the enzyme in these tissues is comparable to that in the liver, lower than the level in the heart and considerably higher than the levels in brain tissue. At all these sites except the heart, immunoblot analysis revealed the existence of two tTG bands of very similar electrophoretic mobility.

To localize the sites of expression and accumulation of tissue transglutaminase within the structures of the developing limb, tissue sections from anterior and posterior limbs of E7.5 embryos were subject to in situ hybridization analysis with chicken heart transglutaminase cRNA probes and to immunohistochemical staining with anti-tTG antibodies (Figures 4-9). In superficial sections of the limb paddle (Figure 4) the hybridization signal specifically localized to the distal segments of the $\mathrm{V}$-shaped interdigital regions between digits 1 and 2 and 2 and 3 of the hind limb (Figure $4 \mathrm{~b}$ ) and digits 2 and 3 of the forelimb (not shown). Brightfield microscopy (Figure $4 \mathrm{a}$ ) of these regions showed the presence of numerous apoptotic cells in these interdigital zones. Immunochemical analysis of the same region showed immunoreactivity concentrated in clusters of

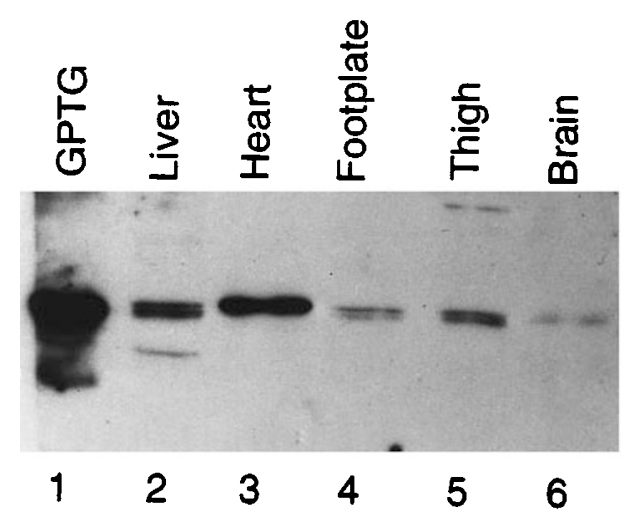

Figure 3 Detection of tissue transglutaminase in E7.5 chicken tissues by immunoblotting. Tissue homogenates from E7.5 chicken embryos were separated on a $10 \%$ polyacrylamide gel, electroblotted to PVDF membrane and reacted with a goat anti-guinea pig transglutaminase antibody followed by HRPO-conjugated rabbit anti-goat IgG and chemiluminescent (ECL) detection. In limbs, liver, and brain tTG is detected as a doublet whereas in the heart a single band is seen. GPTG: $20 \mathrm{ng}$ guinea pig liver transglutaminase apoptotic cells (Figure 5b). Much of the immunostaining was associated with apoptotic cells engulfed by phagocytes but fragments and free-lying cells which showed characteristic apoptotic morphology both with and without nuclear remnants were also labeled.

Figure 6 shows the results obtained in a section that transected the cartilaginous core of the hind limb metatarsals and phalanges. By in situ hybridization tTG mRNA could be detected in the hypertrophic chondrocytes of the prospective primary ossification centers whereas the less mature proliferating chondrocytes of the metaphyseal regions did not label (Figure $6 a$ and b). The epiphyseal regions of the developing bones exhibited a weak, more diffuse, hybridization signal which could be detected only after prolonged ( $>2$ week) exposure (Figure $6 c$ and $d$ ). The epiphyseal (pre)cartilage and periarticular mesenchyme both contributed to this signal. Immunohistochemical analysis revealed that induction of the transglutaminase mRNA is paralleled by the accumulation of the enzyme (Figure 7). Tissue transglutaminase accumulates both in the cytoplasm and in the extracellular matrix (Figure $7 \mathrm{~b}$ and c). To ascertain that an artificial translocation of the enzyme
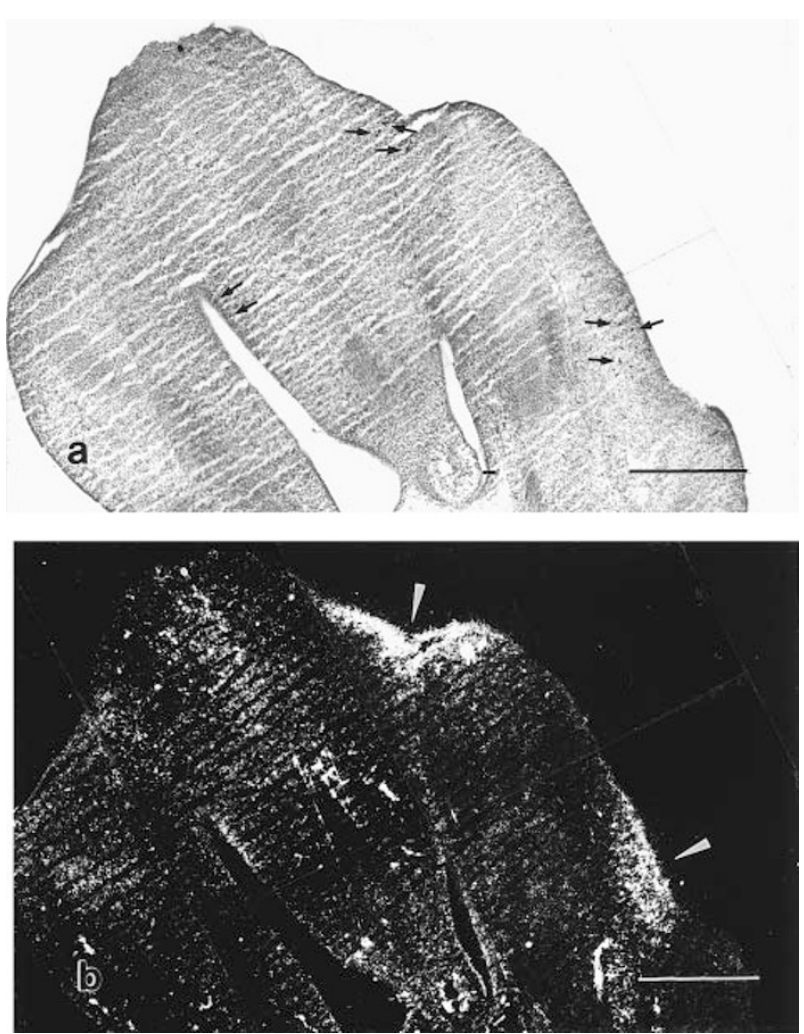

Figure 4 Expression of tissue transglutaminase mRNA in the interdigital web. Formaldehyde-fixed cryostat sections of E7.5 chicken hind limb were subjected to in situ hybridization with $\alpha-{ }^{35}$ S-labeled antisense TTG CRNA. The composites of the distal part of the foot plate comprising digits I-IV in transmitted light (a) and dark field (b) show strong hybridization signal in the wedge-shaped areas between digits 1 \& 2 and 2 \& 3 (arrowheads), corresponding to the distal portion of the respective webs. Arrows in the brightfield photograph indicate apoptotic clusters. This plane of section does not include the cartilaginous cores of the digits. Bar, $0.5 \mathrm{~mm}$ 


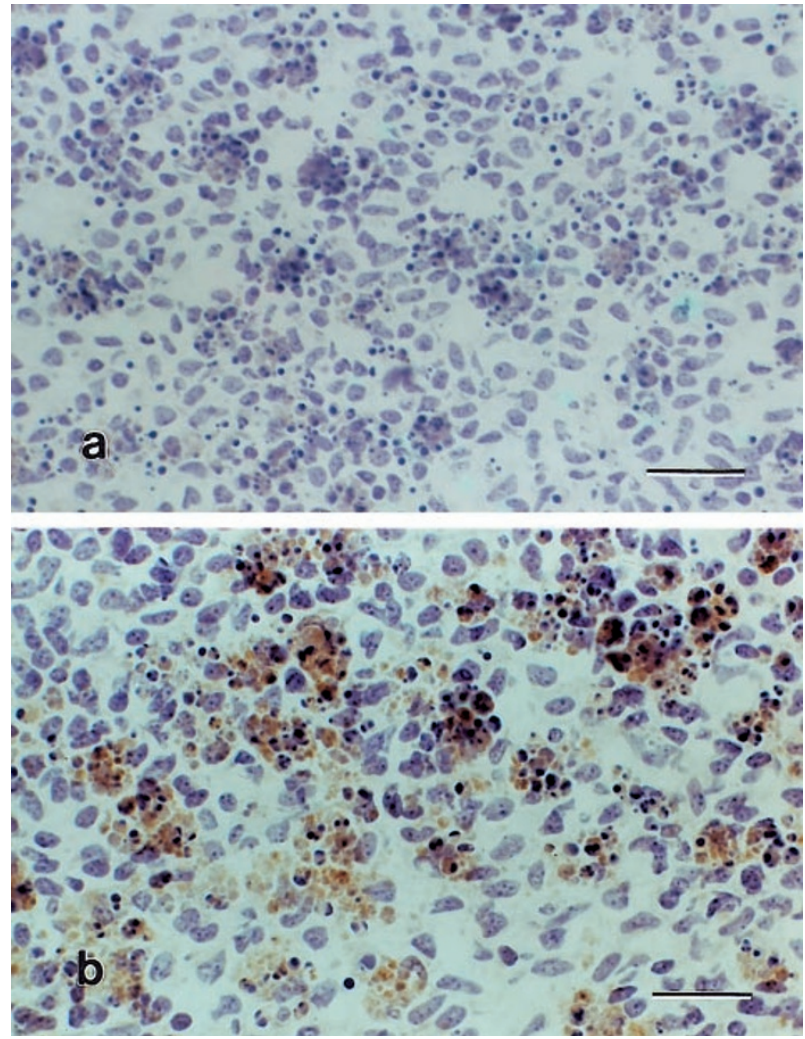

Figure 5 Immunohistochemical detection of tTG in apoptotic cells of E7.5 chicken hind limb interdigital web. Paraformaldehyde-fixed cryostat sections of E7.5 chicken hind limb were subjected to immunodetection of tTG using an affinity purified goat anti-guinea pig antibody followed by biotinylated anti-goat IgG and avidin-biotin-peroxidase complex. (a) Section treated with preimmune serum. Note clustering of apoptotic cells due to phagocytic uptake. Bar, $50 \mu \mathrm{m}$. (b) Apoptotic cells and fragments selectively label with the antitransglutaminase antibody in the lower panel. Bar, $25 \mu \mathrm{m}$

to extracellular matrix components does not take place ${ }^{20}$ these studies were performed on fixed tissues.

There was a low level of transglutaminase and tTG mRNA expression in the hypocellular, loose network of subepithelial mesenchyme. In the tarso-metatarsal area in situ hybridization detected a strip of very strongly labeled mesenchyme along the posterior border of the hind limb after extended autoradiographic exposure (6-8 weeks), which extended onto the footplate peripheral to the marginal sinus whereas was centrally located to it at more proximal levels (Figure 8). This strip of mesenchymal tissue, which could be identified in immunostained sections as well (not shown), does not bear any distinguishing morphological characteristics.

\section{Expression of transglutaminase in muscle precursors}

In situ hybridization analysis of the expression in the proximal limb also revealed specific hybridization of the cRNA probe to developing skeletal muscle (Figure 9a). The labeling was diffuse and of low intensity. Immunochemical analysis of these structures indicated that skeletal muscle at this stage is primarily comprised of mononuclear myoblasts which arrange into bundles but do not yet fuse to form myotubes. Myoblasts with characteristic apoptotic morphology could be found in the developing muscle. These apoptotic myoblasts accumulated particularly high levels of the enzyme (Figure 9b).

\section{Discussion}

\section{Induction of transglutaminase in apoptosis}

Tissue transglutaminase accumulates in apoptotic cells induced by a variety of experimental manipulations. In cultured cells the enzyme has been identified in apoptotic hepatocytes, ${ }^{25,30}$ hepatoma, ${ }^{25}$ neuroblastoma, ${ }^{44}$ tracheal epithelial $^{45}$ and myeloid leukemia ${ }^{46}$ cells. Accumulation of transglutaminase to high levels in vivo has been detected following lead intoxication in hepatocytes, ${ }^{28}$ and in several organ models of atrophy-associated apoptosis. ${ }^{47,48}$ We have been interested whether parallel accumulations of the enzyme occur in cells undergoing normal or 'physiological' programmed cell death. To address this issue we have examined the levels of tTG expression, as reflected both in accumulations of transglutaminase mRNA and protein, in the developing limb of the chicken embryo. During limb development there is a synchronous wave of cell death in the interdigital web of various vertebrates, contributing to the formation of the fingers. In the chicken embryo this peaks at embryonic day 7.5-8, resulting in the separation of the fingers by day $8.5 .^{49}$ Morphologically the process is typical of apoptosis. By in situ hybridization we were able to detect accumulation of transglutaminase mRNA in the interdigital area simultaneously with the appearance of apoptotic cells and clusters. The enzyme accumulated in clusters of cells that were clearly apoptotic. It is striking that there is considerable heterogeneity in the level of enzyme detected in different clusters of apoptotic cells. While this heterogeneity might reflect technical problems associated with the penetration of antibodies into heavily cross-linked cells, we believe that it is more likely to reflect true heterogeneity in cells undergoing apoptosis. The basis of this heterogeneity, which has been observed in other models of apoptosis, ${ }^{46}$ is not well understood at this time.

While there is extensive evidence suggesting that tTG is induced in many forms of apoptosis, it is much less clear what contribution the enzyme makes to the apoptotic program. Tissue transglutaminase catalyzes protein crosslinking. Isopeptide-crosslinked proteins accumulate to high levels in apoptotic cells ${ }^{28,29}$ and contribute to the stability of the fragments (apoptotic bodies) formed during apoptosis. TTG is also a GTP-binding protein ${ }^{50-52}$ that has been shown to regulate the activity of membrane-bound phospholipase $C^{26,53}$ It is possible that the induction and activation of the enzyme contributes to increased phospholipase activity in the apoptotic cells that may, in turn, facilitate membrane blebbing and cellular fragmentation. Both activities of tTG may contribute to its function in apoptotic interdigital cells.

Although our studies have concentrated on the expression of tTG in interdigital mesenchymal cells, apoptosis can be identified in other tissues involved in limb morphogen- 

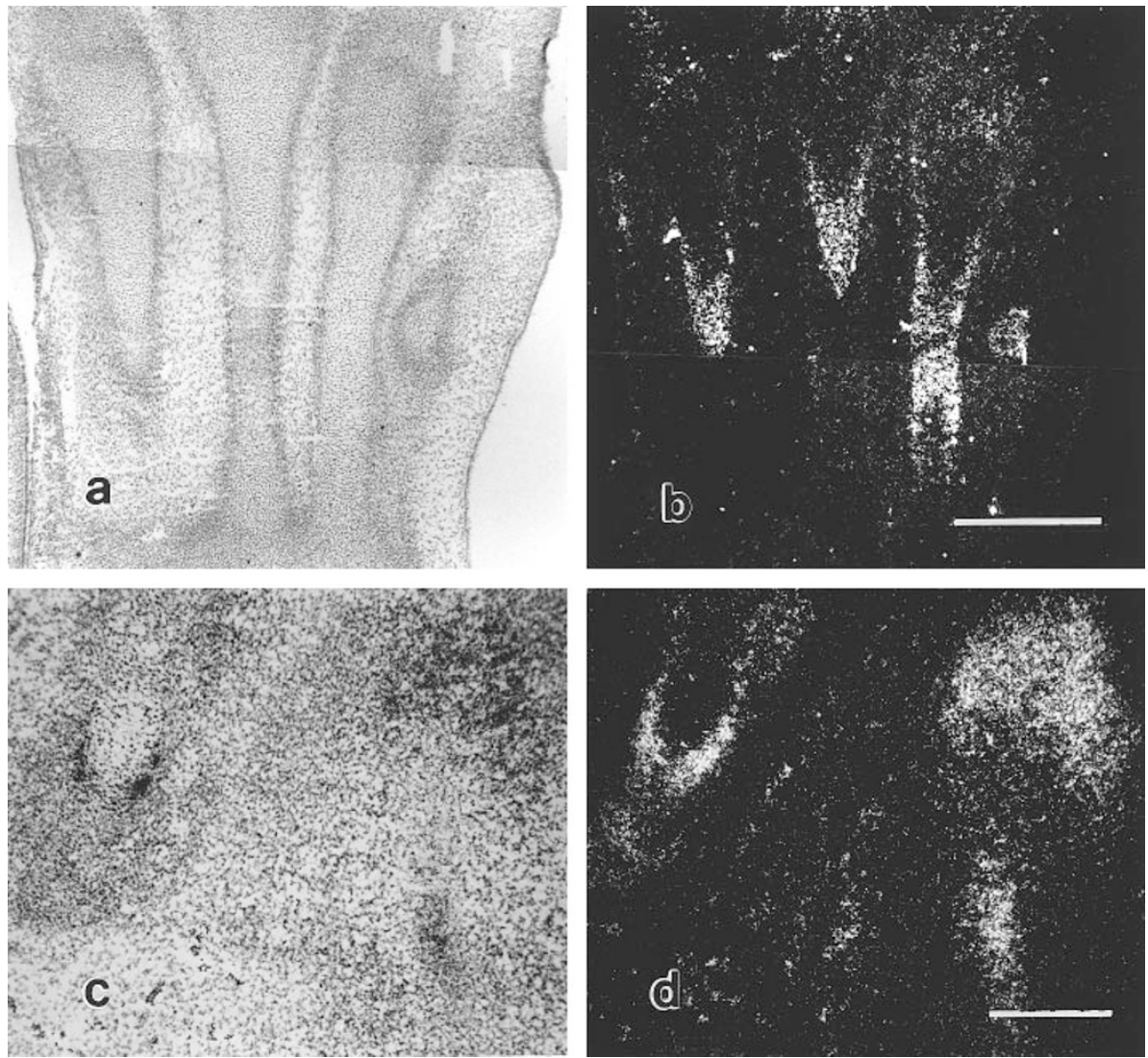

Figure 6 Expression of tTG mRNA in skeletal structures of E7.5 chicken hind limb. Cryostat sections of E7.5 chicken hind limb were subjected to in situ hybridization with $\alpha-{ }^{35}$ S-labeled antisense tTG cRNA. (a) Brightfield of hind limb metatarsals. The slender central portion contains the prospective primary ossification center, the bulbous ends represents the epiphyses. (b) Intense hybridization signal confined to the hypertrophic chondrocytes of the prospective primary ossification center of the metatarsals, the epiphyseal areas label only slightly above background. Two-week exposure. (a and $\mathbf{b})$ composite; bar, $0.5 \mathrm{~mm}$. (c) Brightfield of the metatarso-phalangeal area of two adjacent digits. (d) Darkfield view of the field shown in (c); 6 week exposure detects hybridization signal of the epiphyseal (pre)cartilage and mesenchymal cells of a forming joint of digit III (upper right corner); the U-shaped hybridization signal at left center corresponds to a sleeve of hypertrophic chondrocytes in the middle portion of the para-axially cut metatarsal IV. (c and d) Bar, $200 \mu \mathrm{m}$

esis. ${ }^{54}$ Apoptotic muscle cells have been described during skeletal muscle development. ${ }^{55}$ We observed apoptotic myoblasts during early development of striated muscle characterized by migration and fusion of the myoblasts to form myotubes. In the day 7.5 embryonic limb apoptotic myoblasts were scattered in developing leg and thigh skeletal muscle. The cytoplasm of many of these isolated apoptotic myoblasts also accumulated transglutaminase protein indicating that the induction of the enzyme is common to various forms of physiological apoptosis.

The localization of expression of the endogenous tissue transglutaminase gene in the interdigital web of the day 7.5 chick embryo is identical to that observed in E13.5 mouse embryos transgenic for a $4 \mathrm{~kb}$ segment of the mouse tTG promoter/ $\beta$-galactosidase construct. ${ }^{56}$

\section{Induction of transglutaminase during chondrogenesis}

Skeletal development in the limb is initiated by the condensation of precartilage mesenchymal cells, followed by differentiation to form a cartilaginous template which, in turn, is replaced by endochondral bone. We found by in situ hybridization that the precartilaginous mesenchyme, the hypertrophic chondrocytes, and the surrounding perichondrium expressed transglutaminase mRNA. The association of transglutaminase with hypertrophic cartilage is similar to its pattern of expression in the mammalian growth plate, ${ }^{57}$ the structure responsible for the postnatal growth of long bones. Aeschlimann et al. ${ }^{57}$ have demonstrated in the epiphyseal cartilage of newborn rats that increasing expression of transglutaminase parallels the maturation of the cartilage. Tissue transglutaminase synthesized by these maturing chondrocytes has been shown to catalyze the covalent cross-linking of extracellular matrix proteins, ${ }^{58,59}$ thereby contributing to the stability of the cartilaginous matrix. Histological analysis of hypertrophic cartilage from formaldehyde-fixed embryonic chicken limbs demonstrated that transglutaminase, as well as accumulating intracellularly, was also deposited in the inter-territorial cartilage matrix. The use of fixed tissue for cryosectioning precludes the possibility of the artefactual translocation of the enzyme from the cytoplasm to components of the extracellular matrix. The deposition of transglutaminase in the extracellular matrix precedes the destruction of the hypertrophic chondrocytes and it is likely to represent active secretion from viable cells. 

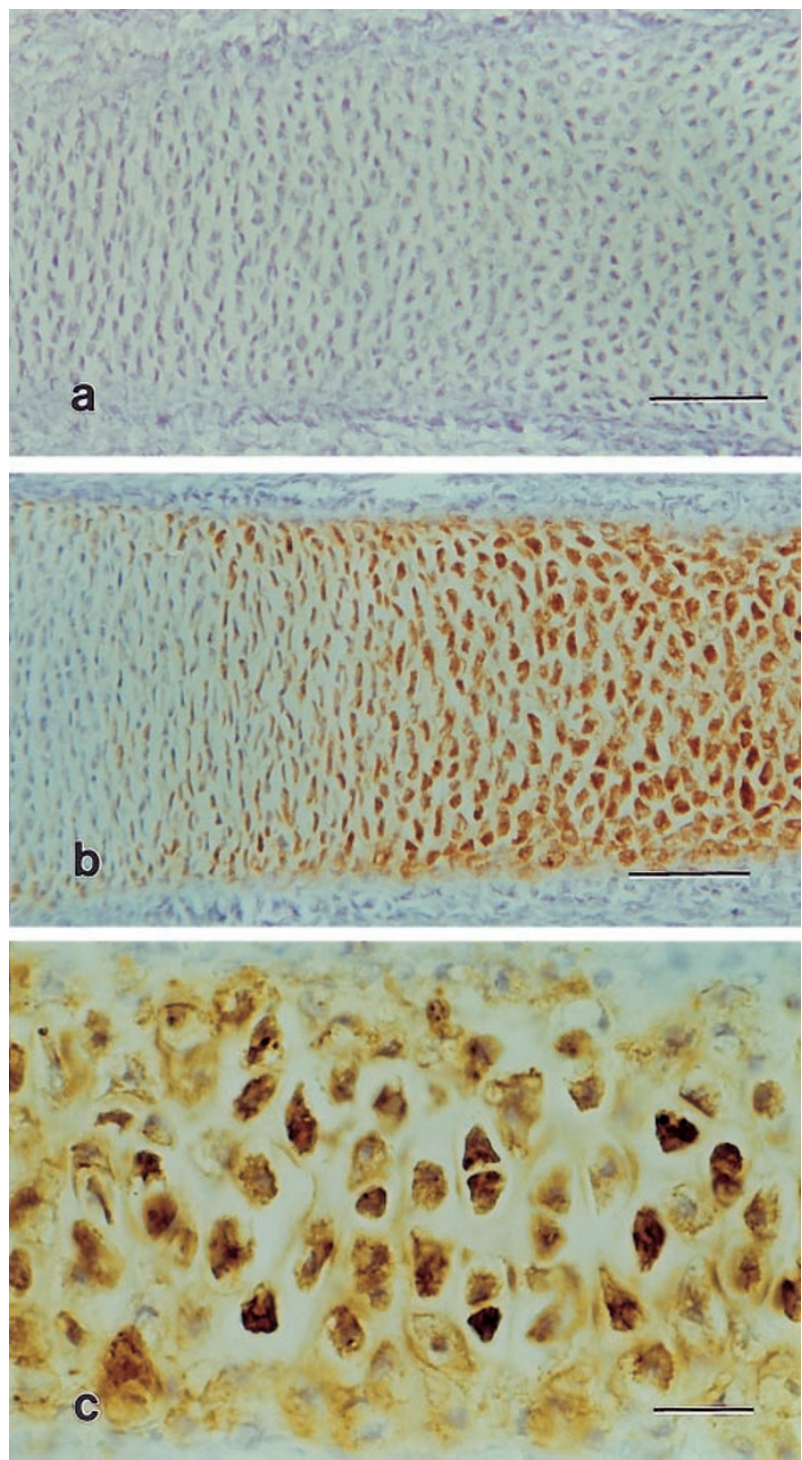

Figure 7 Differentiation stage-specific expression of tissue transglutaminase in cartilage during endochondral ossification. Formaldehyde-fixed cryostat sections of E7.5 chicken hind limb were subjected to chondroitinase $A B C$ treatment and immunohistochemical labeling with non-immune serum (a), or affinity purified goat anti-guinea pig liver transglutaminase ( $\mathbf{b}$ and $\mathbf{c}$ ) followed by $A B C$-peroxidase detection. (a and $\mathbf{b}$ ) Metatarsal cartilage with spindleshaped, non-differentiated chondrocytes at left; and round, plump hypertrophic chondrocytes at right. Note lack of labeling in the control section (a); accumulation of transglutaminase parallels the transition of the resting chondrocytes to the hypertrophic chondrocyte zone. (c) TTG in the hypertrophic zone accumulates both intracellularly and in the interterritorial matrix. (a and b) bar, $75 \mu \mathrm{m}$, (c) $25 \mu \mathrm{m}$

The observation of transglutaminase expression in the precartilage of the epiphysis and (pre)articular mesenchyme indicates that, in addition to ossification, transglutaminase activity might contribute to joint formation. It is interesting to note that transglutaminase expression apparently is associated with specific phases of skeletal development, with striking downregulation in the intervening phases such as the proliferating cartilage phase. The coordinate regulation of enzyme and potential substrates is

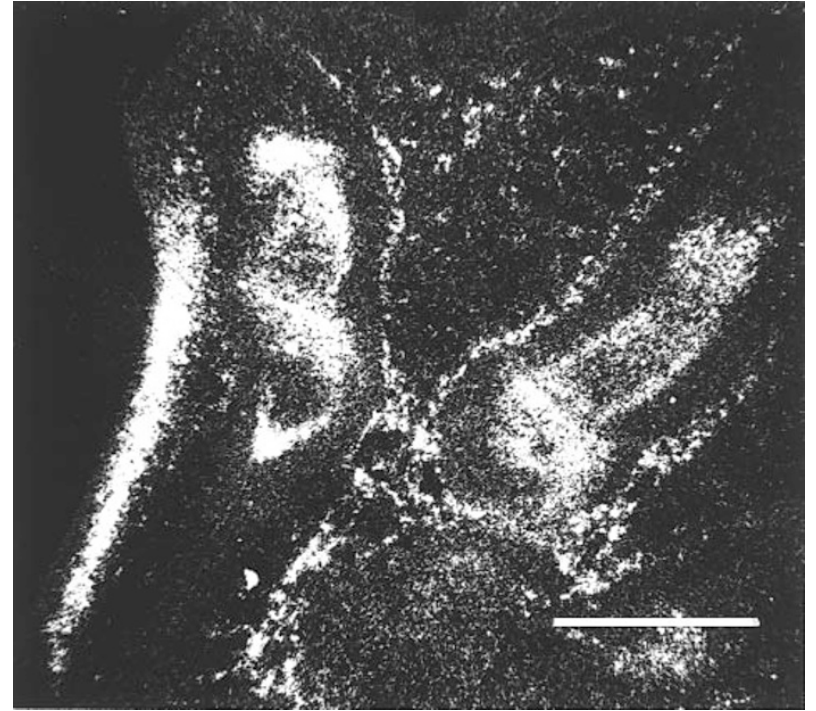

Figure 8 Expression of tissue transglutaminase mRNA in endothelial cells and skeletal structures. Cryostat section of day 7.5 embryonic chicken hind limb was subjected to in situ hybridization with $\alpha-{ }^{35}$ UTP-labeled antisense cRNA. Low power darkfield image following 2 months of autoradiographic exposure. Hypertrophic chondrocytes of the shafts of metatarsals and proximal phalanges as well as mesenchymal cells in the periarticular area label intensely. Running parallel to the digits endothelial cells of the interdigital vessels are visualized. Scattered signal in the interdigital web represents macrophages. Intensely labeled subperidermal stripe along posterior edge of footplate does not show any distinguishing histological features. Bar, $0.5 \mathrm{~mm}$

a possible explanation since specific sets of proteins and patterns of their expression are associated with anatomically or developmentally distinct parts of the skeleton. ${ }^{60}$

The widespread expression of tissue transglutaminase during organogenesis in the embryo contrasts sharply with its limited expression in mesenchymal tissues of the adult organism. ${ }^{15}$ The re-appearance of tTG expression during tissue repair and mesenchymal proliferation in adult tissues such as would healing, ${ }^{27}$ the progression of atherosclerotic plaques, ${ }^{61}$ or within fibrohistiocytic tumors ${ }^{62}$ indicates that the enzyme is commonly activated in the context of tissue remodelling.

\section{Materials and methods}

\section{Materials}

Chicken heart cDNA library cloned into $\lambda Z A P$, pBluescript SK II, and pSG5 were purchased from Stratagene (La Jolla, CA, USA). T7 RNA polymerase, RQ1 DNase, T4 polynucelotide kinase, and Riboprobe Gemini II in vitro transcription kit were from Promega Biotec (Madison, WI, USA). T3 RNA polymerase, Sequenase sequencing kit, and BSA were from USB (Cleveland, OH, USA); $\mathrm{S} 1$ nuclease and RNase A from Worthington (Freehold, NJ, USA); $\left[\alpha^{35}\right.$ S $]$ UTP, $\left[\alpha-{ }^{32} \mathrm{P}\right] \mathrm{dATP}$, $\left[\gamma-{ }^{32} \mathrm{P}\right] \mathrm{dATP},\left[{ }^{3} \mathrm{H}\right]$ putrescine from NEN (Boston, MA, USA); and $\left[\alpha^{35}\right.$ S $]$ dATP from Amersham Life Sciences, Inc. (Arlington Heights, IL, USA); restriction endonucleases from New England Biolabs (Beverly, MA, USA) and Boehringer Mannheim (Indianapolis, IN, USA). Dimethylated casein was from Calbiochem (La Jolla, CA, USA), acetic anhydride and DTT from J.T. Baker, Inc. (Phillipsburg, NJ, USA); formamide, paraformaldehyde, and isopentane were purchased 

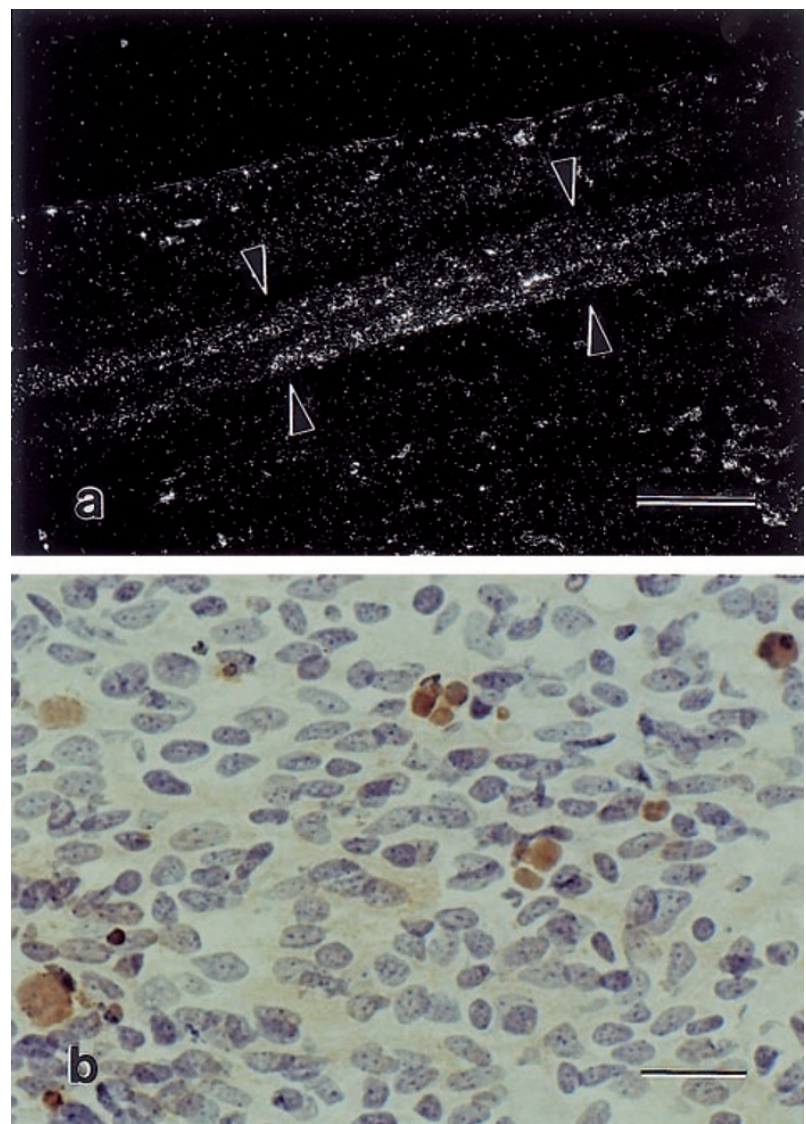

Figure 9 Detection of tissue transglutaminase mRNA and protein in developing skeletal muscle of E7.5 chicken hind limb. (a) Diffuse, low leve hybridization signal in a bundle of developing skeletal muscle (between arrowheads) which runs parallel to the limb surface. Bar, $150 \mu \mathrm{m}$. (b) Immunohistochemical labeling with anti-tTG antibody detects a low level of transglutaminase in the spindle-shaped myoblasts. Myoblasts with apoptotic morphology label intensely. Bar, $25 \mu \mathrm{m}$

from Fluka (Ronkonkoma, NY, USA). O.C.T. compound was from Miles Scientific (Naperville, IL, USA), biotinylated rabbit anti-goat IgG and Vectastain Elite peroxidase kit from Vector Laboratories (Burlingame, CA, USA), Kodak NTB2 emulsion and X-omat film, from Eastman Kodak Co. (Rochester, NY, USA). Other chemicals were from Sigma (St. Louis, MO, USA).

\section{Tissue collection and processing}

Eggs of White Leghorn chickens were incubated in a ventilated incubator at $38^{\circ} \mathrm{C}$. Tissues of chicken embryos were collected at day 7.5 of incubation (E 7.5, $\mathrm{HH}$ stage $32,{ }^{32}$ and fixed in $4 \%$ paraformaldehyde at room temperature for $4 \mathrm{~h}$ for immunohistochemistry or at $4^{\circ} \mathrm{C}$ for $2 \mathrm{~h}$ for in situ hybridization experiments. Limbs were washed at $4^{\circ} \mathrm{C}$ overnight in PBS, embedded in O.C.T. compound, snap-frozen in isopentane chilled with dry ice and cut on a cryostat (Minotome, Boston, MA, USA) at 4-6 $\mu \mathrm{m}$. Sections were picked up on silanized slides.

\section{Antibody}

The affinity purified goat anti-guinea pig liver transglutaminase antibody ${ }^{33}$ detects tTG in cell or tissue homogenates from various sources as a single band in Western blotting experiments.

\section{Immunoblotting}

Tissue samples from 7.5-8-day chicken embryos were collected and homogenized in $20 \mathrm{mM}$ Tris/1 mM EDTA, pH 7.5 by mincing followed by sonication on ice. Protein concentration of the homogenates was determined by the Bio-Rad Protein Assay kit (Bio-Rad, Hercules, CA, USA) with BSA as the standard. Lysates were denatured by boiling for $2 \mathrm{~min}$ in SDS sample buffer containing $20 \mathrm{mM}$ Tris, pH 7.5, 1\% SDS, $0.75 \mathrm{M}$ 2-mercaptoethanol, 2.5\% sucrose, and $0.001 \%$ bromophenol blue. Solubilized extracts were fractionated by electrophoresis on a $10 \%$ polyacrylamide gel and electroblotted onto Immobilon-P membrane (Millipore, Bedford, MA, USA). Filters were blocked in a solution of $1 \%$ non-fat dry milk, $1 \%$ BSA, $50 \mathrm{mM}$ Tris, $\mathrm{pH} 7.5,0.5 \mathrm{M}$ $\mathrm{NaCl}, 0.1$ polyvinylpyrrolidone, $0.1 \%$ Ficoll 400 for $1 \mathrm{~h}$ with rocking. Affinity purified goat anti-guinea pig liver transglutaminase antibody was applied at $1 \mu \mathrm{g} / \mathrm{ml}$ in the above blocking solution for $2 \mathrm{~h}$ at room temperature. Filters were washed six times for $5 \mathrm{~min}$ in $1 \%$ non-fat dry milk, $20 \mathrm{mM}$ Tris, pH 7.5, 0.5 M NaCl, 0.1\% Triton X-100 (Sigma). The secondary antibody was a HRP-conjugated affinity purified rabbit antigoat IgG (Sigma A5420) applied at a dilution of 1:10,000 for $1 \mathrm{~h}$ in blocking solution, following which the filters were washed as above, and antigen-antibody complexes were identified by chemiluminescent detection using the ECL kit (Amersham Life Sciences, Inc., Arlington Heights, IL, USA) according to the manufacturer's instructions.

\section{Immunohistochemistry}

Cryostat sections of paraformaldehyde-fixed tissues were used. Sections were air-dried for $3 \mathrm{~h}$ at room temperature. Endogenous peroxidase activity was blocked by $0.1 \mathrm{M}$ periodic acid treatment for $5 \mathrm{~min}$. Sections were covered with a mixture of $1 \%$ gelatin-20\% normal rabbit serum for $20 \mathrm{~min}$ at room temperature. Sections were incubated with affinity purified goat anti-guinea pig liver transglutaminase at $5 \mu \mathrm{g} / \mathrm{ml}$ in $1 \%$ gelatin-20\% normal rabbit serum overnight at room temperature. Control slides were incubated with a 1:1000 dilution of the $\mathrm{IgG}$ fraction of the preimmune serum. Washing was in Tris-buffered saline for $3 \times 10 \mathrm{~min}$. Biotinylated rabbit anti-goat IgG was applied at $1: 150$ dilution in $1 \%$ gelatin $-20 \%$ normal rabbit serum for $45 \mathrm{~min}$ at room temperature. Washing was as above, followed by avidin-biotinylated peroxidase complex (Vectastain Elite kit, Vector) according to the manufacturer's instructions. The immunoreaction was visualized by $0.05 \% \mathrm{DAB}-0.001 \% \mathrm{H}_{2} \mathrm{O}_{2}$. Sections were counterstained with Mayer's hemalum, dehydrated and mounted in Permount.

\section{Transglutaminase assay}

To assess enzymatic activity of TTG we used the filter paper assay of Lorand and co-workers. ${ }^{34}$ This assay measures the covalent conjugation of the amine substrate $\left[{ }^{3} \mathrm{H}\right]$ putrescine by the transglutaminase of the cell homogenate to N,N-dimethylated casein in the presence of calcium ions. GTP-inhibition was tested in the presence of $200 \mu \mathrm{M}$ of the non-hydrolyzable GTP-analogue guanosine $5^{\prime} \mathrm{O}-(3-$ thiotriphosphate) (GTP- $\gamma$-S) (Sigma) and $1 \mathrm{mM} \mathrm{Ca}^{2+}$.

\section{Cloning and sequencing of chicken heart tissue transglutaminase cDNA}

An adult chicken heart cDNA library, cloned into the EcoRI site of the IZAP vector, was obtained from Stratagene (La Jolla, CA, USA). Approximately $5 \times 10^{5}$ plaques were screened using a $1.5 \mathrm{kbp}$ partial cDNA clone of mouse tTG as probe. Prehybridization, hybridization, and autoradiography were according to established protocols. ${ }^{35}$ Fourteen clones gave positive signal upon the third round of 
screening. Plasmid subclones in pBluescript were obtained, and linearized plasmids were used in a Southern blotting experiment to determine insert size. Of the two positive clones ctg6a1, a clone containing a $2.8 \mathrm{kbp}$ insert, was used for subsequent hybridization experiments. Partial sequencing of this clone showed that it did not include a translational start site. Using an $0.4 \mathrm{kbp}$ long $5^{\prime} \mathrm{EcoRI}-\mathrm{Stul}$ fragment of this clone we rescreened the library to obtain a clone which contained the whole coding sequence. Using high stringency hybridization and washing conditions 12 positive clones out of $6 \times 10^{5}$ were found. One of these (ctg12) contained a larger EcoRI-Stul fragment than the insert used for screening. Sequencing of chicken transglutaminase cDNAs was carried out by the dideoxy chain termination method ${ }^{36}$ using the Sequenase sequencing kit (USB, Cleveland, $\mathrm{OH}, \mathrm{USA}$ ) or by automated sequencing on an $\mathrm{ABI}$ model 373 sequencer (Foster City, CA, USA) using dye terminator chemistry according to the manufacturer's protocol. The sequence was derived from partial sequencing of $\operatorname{ctg} 12$, ctg6a.1, and overlapping subclones thereof but is contained in its entirely in clone ctg12. The obtained sequence was compared to the human ITG sequence by the NUCALN and PRTALN programs of Wilbur and Lipman ${ }^{37}$ or by the Geneworks software (Intelligenetics, Inc., Campbell, CA, USA).

\section{RNA blotting}

Total cellular RNA from hearts of embryonic chickens or hatchlings was prepared by the guanidine isothiocyanate method ${ }^{38}$ followed by density gradient centrifugation through $5.7 \mathrm{M} \mathrm{CsCl}$ for $18 \mathrm{~h}$ at 35000 r.p.m. in a Beckman SW 50.1 rotor. Ten $\mu \mathrm{g}$ of total RNA was loaded unto a $1 \%$ agarose-2.2 $\mathrm{M}$ formaldehyde gel and run at $60 \mathrm{~V}$ for $3 \mathrm{~h}$ in MOPS running buffer. RNA was transferred to nylon membrane (Stratagene) by capillary transfer in $10 \times$ SSC overnight, and immobilized by UV cross-linking (Stratalinker, Stratagene). Prehybridization and hybridization were for $3 \mathrm{~h}$ and $12 \mathrm{~h}$, respectively, using $10^{6}$ c.p.m. $/ \mathrm{ml}$ of the random-primed labeled chicken transglutaminase cDNA probe. Filters were washed in $1 \times \mathrm{SSC}-0.1 \%$ SDS, $2 \times 15 \mathrm{~min}$ at room temperature, followed by $0.1 \times \mathrm{SSC}-0.1 \%$ SDS, $2 \times 15 \mathrm{~min}$ at $60^{\circ} \mathrm{C}$. Filters were exposed against Kodak Xomat film at $-70^{\circ} \mathrm{C}$ for $12-36 \mathrm{~h}$.

\section{In situ hybridization}

$\left[{ }^{35} \mathrm{~S}\right]$-labeled RNA probes were used for in situ hybridization. Complementary RNAs were prepared by in vitro transcription using the Riboprobe Gemini II kit. pBluescript containing the $2.8 \mathrm{kbp}$ insert (clone 6a.1) was linearized with either $X b a l$ (to obtain antisense transcript) or Sall (to obtain sense transcript) and riboprobes were synthesized according to the manufacturer's protocol using either T3 (USB) or T7 (Promega) RNA polymerases and $\left[\alpha^{-}{ }^{35}\right.$ S $]$ UTP. Following in vitro transcription the DNA template was digested with $1 \mathrm{U}$ of $\mathrm{RQ1}$ DNase (Promega) at $37^{\circ} \mathrm{C}$ for $5 \mathrm{~min}$. Probe size was reduced to approximately $150 \mathrm{nt}$ by limited alkaline hydrolysis at $60^{\circ} \mathrm{C} .^{39}$ Unincorporated label was removed by spinning the probes through Sephadex G 50 column (Boehringer Mannheim, Indianapolis, IN, USA) equilibrated with $20 \mathrm{mM}$ Tris, $\mathrm{pH} 7.6 / 2 \times \mathrm{SSC} / 10 \mathrm{mM}$ DTT.

Limbs of day 7.5 chicken embryos with or without fixation in $4 \%$ paraformaldehyde at $4^{\circ} \mathrm{C}$ for $2 \mathrm{~h}$, were embedded in O.C.T. compound and snap-frozen in isopentane chilled with dry ice. Sections were cut on the cryostat at 4-6 $\mu \mathrm{m}$ nominal thickness, picked up on alkoxysilane-coated slides, briefly air-dried, and fixed with $4 \%$ paraformaldehyde in PBS for $5 \mathrm{~min}$. Tissue pretreatments and hybridization were done according to Harper and Marselle. ${ }^{40}$ Slides were air-dried and exposed at $4{ }^{\circ} \mathrm{C}$ for $6-8$ weeks in the presence of desiccant. Slides were developed with Kodak Dektol developer at $15^{\circ} \mathrm{C}$ for $2 \mathrm{~min}$ and fixed in Kodak rapid fixer.

\section{Transfection}

Full length ctg12 was inserted into the eukaryotic expression vector pSG5 in either orientation. Using these constructs transient transfection of COS-1 cells was carried out by the DEAE-dextran procedure. ${ }^{41}$ Cells were harvested $72 \mathrm{~h}$ after transfection and aliquots of the cell lysate were assayed for transglutaminase activity in the presence or absence of $200 \mu \mathrm{M}$ of GTP- $\gamma-\mathrm{S}$, or subjected to immunoblotting.

\section{Acknowledgements}

We gratefully acknowledge the technical assistance of Ms. Nubia Alban. We thank Dr. Lincoln Gray for providing us with chicken embryos. GenBank accession number U47273.

\section{References}

1. Folk JE and Finlayson JS (1997) The epsilon-(gamma-glutamyl)lysine crosslink and the catalytic role of transglutaminases. Adv. Prot. Chem. 31:1-133

2. Lorand L and Conrad SM (1984) Transglutaminases. Mol. Cell. Biochem. 58: $9-35$

3. Aeschlimann D and Paulsson M (1994) Transglutaminases: protein crosslinking enzymes in tissues and body fluids. Thromb. \& Haemostasis 71: $402-$ 415

4. Greenberg CS, Birckbichler PJ and Rice RH (1991) Transglutaminases: multifunctional cross-linking enzymes that stabilize tissues. FASEB J. 5: 30713077

5. Ho KC, Quarmby VE, French FS and Wilson EM (1992) Molecular cloning of rat prostate transglutaminase complementary DNA. The major androgen-regulated protein DP1 or rat dorsal prostate and coagulating gland. J. Biol. Chem. 267: $12660-12667$

6. Seitz J, Keppler C, Rausch U and Aumuller G (1990) Immunohistochemistry of secretory transglutaminase from rodent prostate. Histochem. 93: 525-530

7. Folk JE (1980) Transglutaminases. Annu. Rev. Biochem. 49: 517-531

8. Laki K and Lorand L (1948) On the solubility of the fibrin clot. Science 108: 280

9. Barry EL and Mosher DF (1988) Factor XIII cross-linking of fibronectin at cellular matrix assembly sites. J. Biol. Chem. 263: 10464-10469

10. Ichinose A, Hendrickson LE, Fujikawa K and Davie EW (1986) Amino acid sequence of the a subunit of human factor XIII. Biochemistry 25: 6900-6906

11. Phillips MA, StewartBE, Qin Q, Chakravarty R, Floyd EE, Jetten AM and Rice RH (1990) Primary structure of keratinocyte transglutaminase. Proc. Natl. Acad. Sci. USA. 87: 9333-9337

12. Polakowska R, Herting $E$ and Goldsmith $L A$ (1991) Isolation of cDNA for human epidermal type I transglutaminase. J. Invest. Dermatol. 96: 285-288

13. Green $\mathrm{H}(1980)$ The keratinocyte as differentiated cell type. Harvey Lectures 74 $101-139$

14. Gentile V, Thomazy V, Piancentini M, Fesus L and Davies PJ (1992) Expression of tissue transglutaminase in Balb-C 3T3 fibroblasts: effects on cellular morphology and adhesion. J. Cell. Biol. 119: 463-474

15. Thomazy V and Fesus $L$ (1989) Differential expression of tissue transglutaminase in human cells. An immunohistochemical study. Cell. Tiss. Res. 255: 215224

16. Trejo-Skalli AV,Velasco PT, Murthy SN, Lorand L and Goldman RD (1995) Association of a transglutaminase-related antigen with intermediate filaments. Proc. Natl. Acad. Sci. USA. 92: 8940-8944

17. Aeschlimann D and Paulsson M (1991) Cross-linking of laminin-nidogen complexes by tissue transglutaminase. A novel mechanism for basement membrane stabilization. J. Biol. Chem. 266: 15308-15317

18. Birckbichler PJ, Orr GR, Paterson Jr MK, Conway E, Carter HA and Maxwell MD (1983) Enhanced transglutaminase activity in transformed human lung fibroblast cells after exposure to sodium butyrate. Biochim. Biophys. Acta. 763: 27-34 
19. Turner PM and Lorand L (1989) Complexation of fibronectin with tissue transglutaminse. Biochem. 28: 628-635

20. Upchurch HF, Conway E, Patterson Jr MK, Birckbichler PJ and Maxwell MD (1987) Cellular transglutaminase has affinity for extracellularmatrix. In Vitro Cell. Devel. Biol. 23: 795-800

21. Barsigian C, Fellin FM, Jain A and Martinez J (1988) Dissociation of fibrinogen and fibronectin binding from transglutaminase-mediated cross-linking at the hepatocyte surface. J. Biol. Chem. 263: 14015-14022

22. Sane DC, Moser TL, Pippen AM, Parker CJ, Achyuthan KE and Greenberg CS (1988) Vitronectin is a substrate for transglutaminases. Biochem. Biophys. Res. Comm. 157: 115-120

23. Kojima S, Nara K and Rifkin DB (1993) Requirement for transglutaminase in the activation of latent transforming growth factor-beta in bovine endothelial cells. J. Cell. Biol. 121: $439-448$

24. Fesus L, Davies PJ and Piacentini M (1991) Apoptosis: molecular mechanisms in programmed cell death. Eur. J. Cell Biol. 56: 170-177

25. Fukuda K, Kojiro M and Chiu JF (1993b) Induction of apoptosis by transforming growth factor-beta 1 in the rat hepatoma cell line McA-RH7777: a possible association with tissue transglutaminase expression. Hepatol. 18: 945-953

26. Nakaoka H, Perez DM, Baek KJ, Das T, Husain A, Misono K, Im MJ and Graham RM (1994)Gh: a GTP-binding protein with transglutaminase activity and receptor signaling function. Science 264: 1593-1596

27. Bowness JM, Tarr AH and Wong T (1988) Increased transglutaminase activity during skin would healing in rats. Biochim. Biophys. Acta. 967: 234-240

28. Fesus L, Thomazy $V$ and Falus $A$ (1987) Induction and activation of tissue transglutaminase during programmed cell death. FEBS Lett. 224: 104-108

29. Fukuda K, Kojiro Mand Chiu JF (1993a) Cross-linked cytokeratin polypeptides in liver and hepatoma cells: possible association with the process of cell degeneration and death. Hepatol. 17: 118-124

30. Piacentini M, Ceru MP, Dini L, Di Rao M, Piredda L, Thomazy V, Davies PJ and Fesus $L$ (1992) In vivo and in vitro induction of 'tissue' transglutaminase in rat hepatocytes by retinoic acid. Biochim. Biophys. Acta. 1135: 171-179

31. Szondy Z, Molnar P, Nemes Z, Boyiadzis M, Kedei N, Toth R and Fesus L (1997) Differential expression of tissue transglutaminase during in vivo apoptosis of thymocytes induced via distinct signalling pathways. FEBS Lett. 404: $307-313$

32. Hamburger $V$ and Hamilton $H L$ (1951) A series of normal stages in the development of the chick embryo. J. Morphol. 88: 49-92

33. Moore Jr WT, Murtaugh MP and Davies PJ (1984) Retinoic acid-induced expression of tissue transglutaminase in mouse peritoneal macrophages. J. Biol. Chem. 259: $12794-12802$

34. Lorand L, Campbell-Wilkes LK and Cooperstein L (1972) A filter paper assay for transamidating enzymes using radioactive amine substrates. Anal. Biochem. 50: $623-631$

35. Ausubel FM, Brent R, Kingston RE, Moore DD, Seidman JG, Smith JA and Struh $\mathrm{K}$ (1994) Current protocols in molecular biology. Current protocols, Janssen K. ed (New York, John Wiley \& Sons, Inc).

36. Sanger F, Nicklen $S$ and Coulson AR (1997) DNA sequencing with chainterminating inhibitors. Proc. Natl. Acad. Sci. USA. 74: 5463-5467

37. Wilbur WJ and Lipman DJ (1983) Rapid similarity searches of nucleic acid and protein data banks. Proc. Natl. Acad. Sci. USA. 80: 726-730

38. Chirgwin JM, Przybyla AE, McDonald RJ and Rutter WJ (1979) Isolation of biologically active ribonucleic acid from sources enriched in ribonuclease. Biochem. 18: 240-255

39. Cox KH, DeLeon DV, Angerer LM and Angerer RC (1984) Detection of mRNAs in sea urchin embryos by in situ hybridization using asymmetric RNA probes. Dev. Biol. 101: 485-502

40. Harper ME and Marselle LM (1987) RNA detection and localization in cells and tissue sections by in situ hybridization of 35S-labeled RNA probes. Methods Enzymol. 151: 539-551
41. Keown WA, Campbell CR and Kucherlapati RS (1990) Methods for introducing DNA into mammalian cells. Methods Enzymol. 185: 527-537

42. Kozak M (1986) Point mutations define a sequence flanking the AUG initiator codon that modulates translation by eukaryotic ribosomes. Cell 44 : 283-292

43. Weraarchakue-Boonmark et al, 1992 in text but not in references

44. Piacentini M and Melino G (1994) Role of tissue transglutaminase in neuroblastoma cells undergoing apoptosis. Prog. Clin. Biol. Res. 385: $123-129$

45. Zhang LX, Mills KJ, Dawson MI, Collins SJ and Jetten AM (1995) Evidence for the involvement of retinoic acid receptor RAR alpha-dependent signaling pathway in the induction of tissue transglutaminase and apoptosis by retinoids. J. Biol. Chem. 270: 6022-6029

46. Nagy L, Thomazy VA, Shipley GL, Fesus L, Lamph W, Heyman RA, Chandraratna RA and Davies PJ (1995) Activation of retinoid X receptors induces apoptosis in HL-60 cell lines. Mol. Cell. Biol. 15: 3540-3551

47. Cummings $M$ (1996) Apoptosis of epithelial cells in vivo involves tissue transglutaminase upregulation. J. Pathol. 179: 288-293

48. Nemes Z, Friis RR, Aeschlimann DSS, Paulsson M and Fesus L (1996) Expression and activation of tissue transglutaminase in apoptotic cells of involuting rodent mammary tissue. Eur. J. Cell Biol. 70: 125-133

49. Saunders JWJ (1996) Death in embryonic systems. Science 154: 604-612

50. Achyuthan KE and Greenberg CS (1987) Identification of a guanosine triphosphate-binding site on guinea pig liver transglutaminase. Role of GTP and calcium ions in modulating activity. J. Biol. Chem. 262: 1901-1906

51. Bergamini CM, Signolrini M and Poltronieri L (1987) Inhibition of erythrocyte transglutaminase by GTP. Biochim. Biophys. Acta 916: 149-151

52. Lee KN, Birckbichler PJ and Patterson Jr MK (1989) GTP hydrolysis by guinea pig liver transglutaminase. Biochem. Biophys. Res. Comm. 162: $1370-1375$

53. Hwang KC, Gray CD, Sivasubramanian N and Im MJ (1995) Interaction site of GTP binding Gh (transglutaminase II) with phospholipase C. J. Biol. Chem. 270: 27058-27062

54. Ernst M (1926) Uber Untergang von Zellen wahrend der normalen Entwicklung bei Wirbeltieren. Zeitschrift fur Anatomie und Entwicklungsgeschichte 79: 228262

55. McClearn D, Medville R and Noden D (1995) Muscle cell death during the development of head and neck muscles in the chick embryo. Dev. Dynam. 202: 365-377

56. Nagy L, Thomázy VA, Saydak MM, Stein JP, Davies PJA (1997) The promoter of the mouse transglutaminase gene directs tissue-specific, retinoid-regulated and apoptosis-linked expression. Cell Death Differ. 4: 534-547

57. Aeschlimann D, Wetterwald A, Fleisch H and Paulsson M (1993) Expression of tissue transglutaminase in skeletal tissues correlates with events of terminal differentiation of chondrocytes. J. Cell. Biol. 120: 1461-1470

58. Aeschlimann D, Kaupp O and Paulsson M (1995) Transglutaminase-catalyzed matrix cross-linking in differentiating cartilage: identification of osteonectin as a major glutaminyl substrate. J. Cell. Biol. 129: 881-892

59. Hohenadl C, Mann K, Mayer U, Timpl R, Paulsson M and Aeschlimann D (1995) Two adjacent N-terminal glutamines of BM-40 (osteonectin, SPARC) act as amine acceptor sites in transglutaminase C-catalyzed modification. J. Biol. Chem. 270: 23415-23420

60. Nalin AM, Greenlee Jr TK and Sandell LJ (1995) Collagen gene expression during development of avian synovial joints: transient expression of types II and XI collagen genes in the joint capsule. Dev. Dynam. 203: 352-362

61. Shainoff JR and Page IH (1972) Deposition of modified fibrinogen within the aortic intima. Atheroscler. 16, 287-305

62. Thomazy V, Nagy A, Gal I and Nemes Z (1994) Plexiform fibrohistiocytic tumour with novel phenotypic features. Histopathol. 25: 165-169 